\title{
Effects of CuO NPs on the pollutant removal, EPS and microbial community of aerobic granular sludge
}

\author{
Xiaoying Zheng ${ }^{1}$, Xiaoyao Shao ${ }^{2}$, Yuan Zhang ${ }^{2}$, Mengmeng $\mathrm{Yang}^{2}$, Zhi Xu ${ }^{2}$ and Linghua $\mathrm{Zhu}^{2}$ \\ ${ }^{1}$ Ministry of Education Key Laboratory of Integrated Regulation and Resource Development on Shallow Lakes, Hohai University, \\ Nanjing 210098, PR China \\ ${ }^{2}$ College of Environment, Hohai University, Nanjing 210098, PR China.
}

\begin{abstract}
With the increasing use of cupric oxide nanoparticles ( $\mathrm{CuO} \mathrm{NPs}$ ), its potential environmental toxicity has been concerned nowadays. Aerobic granular sludge (AGS) is a special collection of microorganisms. This research studied under long exposure to the concentration of 5, 10 and $20 \mathrm{mg} / \mathrm{L}$ of $\mathrm{CuO}$ NPs, pollutants removal efficiency of AGS, extracellular polymers (EPS) and microbial communities in aerobic/anaerobic/anoxic (A/O/A) sequencing batch reactors (SBRs). The results showed that COD removal rates was stable, and the removal efficiencies of TN decreased because of the high concentration $\mathrm{CuO}$ NPs. On the 45th day, the TP removal efficiency of the reactor with CuO NPs concentration of 10 $\mathrm{mg} / \mathrm{L}$ and $20 \mathrm{mg} / \mathrm{L}$ decreased to $55.83 \%$ and $43.72 \%$, respectively. The denitrifying phosphorus removal-aerobic granular sludge (DPR-AGS) had certain resistance to the short-term impact of CuO NPs, and the phosphorus removal ability decreased at the late stage of the impact test. Besides, CuO NPs decreased the stability of DPR-AGS. High-throughput sequencing showed that CuO NPs decreased microbial diversity of DPR-AGS.
\end{abstract}

\section{Introduction}

Cupric oxide nanoparticles (CuO NPs) is a functional nano material, which has been applied in biomedical, catalytic materials, biosensors and other fields. ${ }^{1-3}$ With the large use and abandonment of $\mathrm{CuO}$ NPs, its distribution in the environment continues to accumulate, causing potential harm to the ecological environment system. ${ }^{4} \mathrm{CuO}$ NPs also have shown ecident toxicity in bacteria, ${ }^{1}$ algae,,${ }^{5}$ yeast, protozoa,,${ }^{6}$ mammalian cells, ${ }^{7}$ and Daphnia magna. ${ }^{8}$ Aerobic granular sludge (AGS) not only has a good adaptability to the refractory organic matter in sewage, but also has a good adsorption capacity, high efficiency and good selectivity. It can be used to remove heavy metals and nanoparticles in wastewater and achieve a better treatment effect. ${ }^{9,10}$ To our knowledge, there is little information available to evaluate the long-term effects of $\mathrm{CuO}$ NPs on AGS performance (pollutant removal efficiencies), extracellular polymeric substances (EPS) and microbial community.

Therefore, the major purposes of this study were to display the long-term effects of $\mathrm{CuO}$ NPs on the pollutant removal, extracellular polymeric substances (EPS) and microbial diversity of AGS in an A/O/A SBR and to evaluate the variations in microbial richness and diversity in the aerobic granular sludge at different $\mathrm{CuO}$ NPs concentrations through high-throughput sequencing.

\section{Materials and methods}

\subsection{Preparation of CuO NPs suspension}

$50 \mathrm{mg} \mathrm{CuO} \mathrm{NPs} \mathrm{was} \mathrm{weighed} \mathrm{and} \mathrm{added} \mathrm{into} \mathrm{a} 1 \mathrm{~L}$ volumetric flask, Milli-Q water and proper amount of dispersant (SDBS) were added, and the volumetric flask was placed in an ultrasonic cleaning machine for ultrasonic shock for $1.5 \sim 2 \mathrm{~h}\left(25^{\circ} \mathrm{C}, 120 \mathrm{~W}, 40 \mathrm{kHz}\right)$. After the ultrasound, $50 \mathrm{mg} / \mathrm{L} \mathrm{CuO} \mathrm{NPs} \mathrm{suspension} \mathrm{was}$ obtained, and a certain proportion of dilution was carried out to obtain the concentration used in the test $(5,10,20$ $\mathrm{mg} / \mathrm{L})$.

\subsection{Set-up and operation of granular SBR}

Designed parallel running of SBR reactor 4 sets of dynamic simulation test device $(\Phi * \mathrm{H}=120 * 700 \mathrm{~mm})$. The operation cycle of the test was $6 \mathrm{~h}$, and the single cycle successively included inlet water, anaerobic, aerobic, hypoxia, precipitation and drainage. Water is transported to the reactor by peristaltic pump from the bucket and aerated by the micro-hole aerator installed at the bottom. After the reaction, the water is controlled by the solenoid valve and the drainage ratio is $2 / 3$. The composition synthetic wastewater was shown below (mg/L): $\mathrm{COD}, 280 ; \mathrm{NH}_{4}{ }^{+}-\mathrm{N}, 40 ; \mathrm{PO}_{4}{ }^{3-}, 20 ; \mathrm{CaCl}_{2}, 70$; $\mathrm{MgSO}_{4}, 28 ; \mathrm{FeSO}_{4}, 28 ; \mathrm{FeCl}_{3} \cdot 6 \mathrm{H}_{2} \mathrm{O}, 1.50 ; \mathrm{MnCl}_{2} \cdot 4 \mathrm{H}_{2} \mathrm{O}$, 
0.12; $\mathrm{Co}\left(\mathrm{NO}_{3}\right)_{2} \cdot 6 \mathrm{H}_{2} \mathrm{O}, 0.18 ; \mathrm{ZnSO}_{4} \cdot 7 \mathrm{H}_{2} \mathrm{O}, 0.12 ; \mathrm{KI}$, $0.03 ; \mathrm{CuSO}_{4} \cdot 5 \mathrm{H}_{2} \mathrm{O}, 0.03 ; \mathrm{Na}_{2} \mathrm{MoO}_{4} \cdot 2 \mathrm{H}_{2} \mathrm{O}, 0.06 ; \mathrm{H}_{3} \mathrm{BO}_{3}$, 0.15 . $\mathrm{CuO} \mathrm{NPs}$ of different concentrations were added according to the specific test content. During the test, the ambient temperature of the reactor was kept at about $25^{\circ} \mathrm{C}$ and the $\mathrm{pH}$ of the test water was kept at about $7{ }^{\circ} \mathrm{C}$.

\subsection{Evaluation of microbial community in AGS}

The sludge samples successfully granulated with appropriate amount were respectively taken for high-throughput sequencing. The test samples were static settled for $30 \mathrm{~min}$ and centrifuged, then stored at low temperature, and then sent to the gene sequencing company (Shanghai sangong) for sequencing. DNA was extracted by Ezup column soil genomic DNA extraction kit. The extracted DNA samples were stored at $-20{ }^{\circ} \mathrm{C}$ until use. Then, the microbial diversity and composition of each AGS sample were determined by using part $16 \mathrm{~S}$ rDNA based on high-throughput sequencing. PCR amplification was based on the primers $314 \mathrm{~F}$ (CCCTACACGACGCTCTTCCG

ATCTGCCTACGGGNGGCWGCAG) and 805R (GACTGGAGTTCCTTGGC

ACCCGAGAATTCCAGACTACHVGGGTATCTAATC $\mathrm{C})$ in the V3 and V4 regions of $16 \mathrm{~S}$ rDNA. MiSeq sequencing was used for high-throughput sequencing, and the structure of sludge community was subsequently analyzed through species taxonomy.

\section{Results and discussion}

\subsection{Long-term effects of CuO NPs on pollutant removal of DPR-AGS}

The effect of $\mathrm{CuO}$ NPs with different concentrations on pollutant removal of DPR-AGS is shown in Figure 1. It can be seen from Figure 1(a) that the influent COD concentration of each reactor was controlled at $300 \pm 15$ $\mathrm{mg} / \mathrm{L}$. After $45 \mathrm{~d}$ operation, the final effluent COD concentration of the reactor stabilized at $13.15 \mathrm{mg} / \mathrm{L}$, $17.51 \mathrm{mg} / \mathrm{L}, 12.80 \mathrm{mg} / \mathrm{L}$ and $16.23 \mathrm{mg} / \mathrm{L}$ when the concentration of $\mathrm{CuO}$ NPs was $0,5,10$ and $20 \mathrm{mg} / \mathrm{L}$, respectively. The corresponding COD removal efficiency was as high as $95.81 \%, 94.41 \%, 95.92 \%$ and $94.82 \%$. During the whole test period, the COD removal rate of the reactor under the exposure to $\mathrm{CuO}$ NPs of different concentrations can be maintained above $90 \%$, so it can be seen that different concentrations of $\mathrm{CuO}$ NPs have little impact on the COD removal performance of the DPR-AGS.

TN concentration of effluent from the reactor was controlled at $45 \pm 3 \mathrm{mg} / \mathrm{L}$. After adding different concentrations of $\mathrm{CuO} \mathrm{NPs}$, the overall $\mathrm{TN}$ concentration of the effluent from the four reactors did not fluctuate much. At the end of the experiment, the TN concentrations of the effluent with $\mathrm{CuO}$ NPs concentration of $0,5,10$ and $20 \mathrm{mg} / \mathrm{L}$ were $1.59 \mathrm{mg} / \mathrm{L}$, $1.47 \mathrm{mg} / \mathrm{L}, 2.42 \mathrm{mg} / \mathrm{L}$ and $2.70 \mathrm{mg} / \mathrm{L}$ (Figure 1(b)). High concentration of $\mathrm{CuO}$ NPs reduced the effects of DPR-AGS on TN removal.

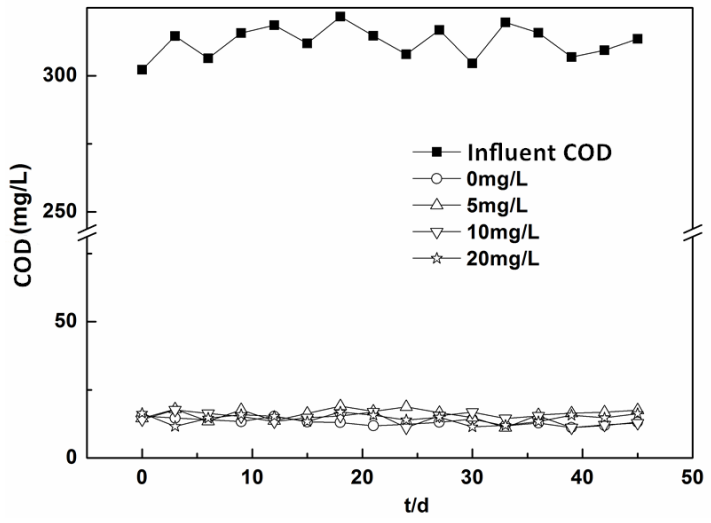

(a) COD

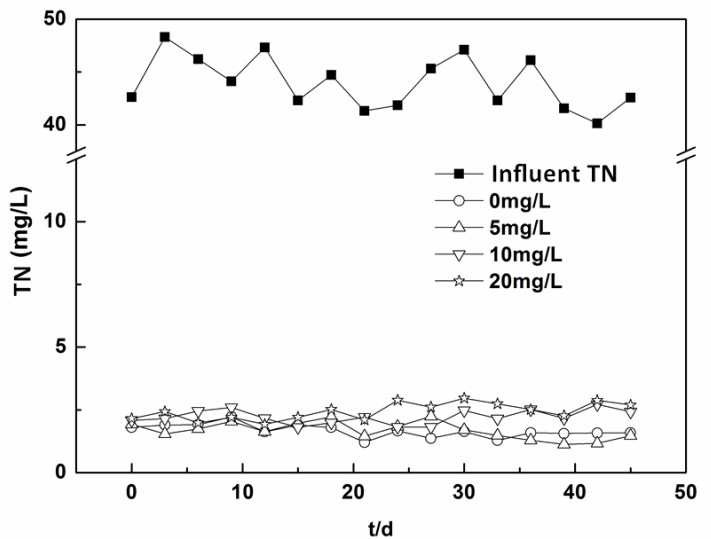

(b) TN

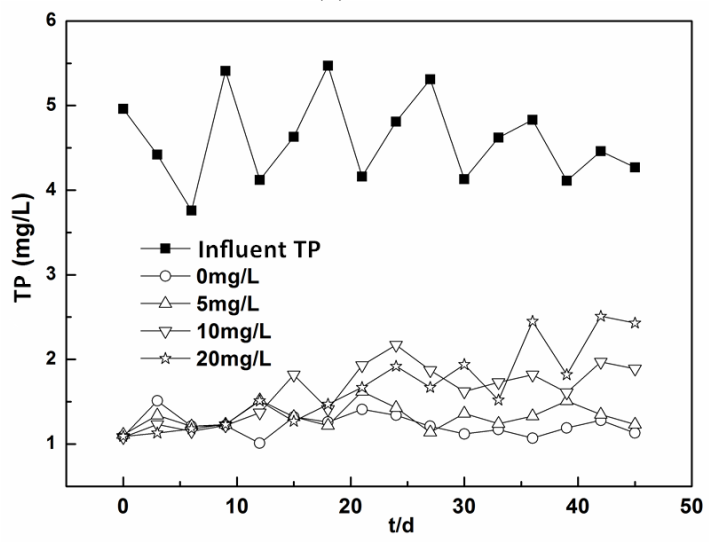

(c) TP

Figure 1. Effects of CuO NPs on the removal of (a) COD, (b) $\mathrm{TN}$ and (c) TP in the AGS reactors.

After the operation of each reactor for $15 \mathrm{~d}$, as shown in Figure 1(c), the TP concentration in the effluent basically remained at $1 \pm 0.5 \mathrm{mg} / \mathrm{L}$, indicating that the DPR-AGS had certain resistance to the short time impact of $\mathrm{CuO}$ NPs, and the high concentration of $\mathrm{CuO}$ NPs had little impact on the phosphorus removal effect of the DPR-AGS in a short time. On the $25 \mathrm{~d}$, when the concentration of $\mathrm{CuO} \mathrm{NPs}$ was $10 \mathrm{mg} / \mathrm{L}$ and $20 \mathrm{mg} / \mathrm{L}$, the TP concentration of the effluent was significantly increased to $2.17 \mathrm{mg} / \mathrm{L}$ and $1.92 \mathrm{mg} / \mathrm{L}$. At the end of the impact test, the TP removal efficiency of the reactor with the concentration of $10 \mathrm{mg} / \mathrm{L}$ and $20 \mathrm{mg} / \mathrm{L}$ of $\mathrm{CuO}$ NPs dropped to $55.83 \%$ and $43.72 \%$. According to the analysis, the continuous accumulation of CuO NPs in the reactor and the enhancement of toxicity had an inhibitory 
effect on the growth of relevant functional microorganisms in the DPR-AGS, leading to the decline of the TP removal efficiencies during long-term $\mathrm{CuO}$ NPs exposure.

\subsection{Sludge properties during CuO NPs exposure}

The influences of different concentrations of $\mathrm{CuO}$ NPs on the microstructure of AGS are shown in Figure 2 and Figure 3. After the addition of $\mathrm{CuO}$ NPs for 20d, the overall microstructure of AGS under the exposure to $\mathrm{CuO}$ NPs of different concentrations was not significantly damaged. Scanning electron microscope showed that sludge in different reactors could maintain granular structure, indicating that AGS formed under $\mathrm{CuO}$ NPs stress had a certain tolerance to $\mathrm{CuO}$ NPs. During the initial stage of $\mathrm{CuO}$ NPs impact test, AGS could resist the impact of $\mathrm{CuO}$ NPs through self-regulation. However, during the experiment, after the addition of $\mathrm{CuO}$ NPs on the 45th day, scanning electron microscope results of AGS showed that the granular structure of the sludge changed to different degrees, among which, the granular structure of the sludge under the exposure to $20 \mathrm{mg} / \mathrm{L} \mathrm{CuO} \mathrm{NPs} \mathrm{changed}$ most significantly, and the granular structure of the sludge developed from ellipsoidal to flat. Under the exposure to $\mathrm{CuO} \mathrm{NPs}$ at $5 \mathrm{mg} / \mathrm{L}$ and $10 \mathrm{mg} / \mathrm{L}$, the granular structure of the sludge changed from dense to loose, but still able to maintain the ellipsoidal structure of the granular sludge. The stability of the granular sludge had little influence, indicating that the experimental sludge had a better resistance to the $\mathrm{CuO}$ NPs within $10 \mathrm{mg} / \mathrm{L}$, while the $\mathrm{CuO}$ NPs at $20 \mathrm{~m} / \mathrm{L}$ had a greater influence on the stability of the AGS, and the AGS system was prone to disintegration under the impact of high concentration of $\mathrm{CuO}$ NPs.

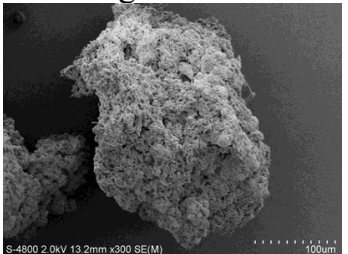

a. $0 \mathrm{mg} / \mathrm{L}$

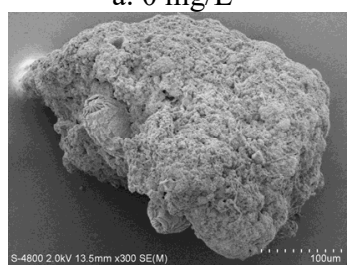

c. $10 \mathrm{mg} / \mathrm{L}$

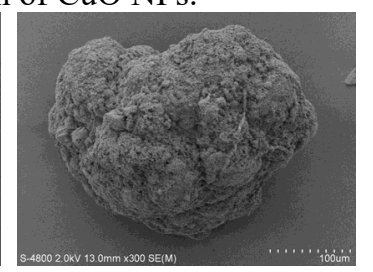
b. $5 \mathrm{mg} / \mathrm{L}$

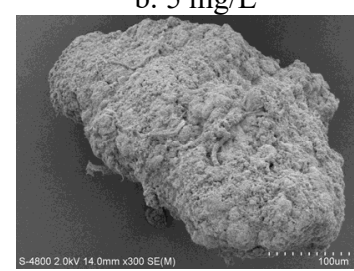

d. $20 \mathrm{mg} / \mathrm{L}$

Figure 2. High concentration $\mathrm{CuO}$ NPs impact on the 20th day AGS microstructure ×300 (SEM)

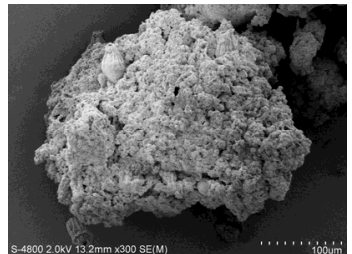

a. $0 \mathrm{mg} / \mathrm{L}$

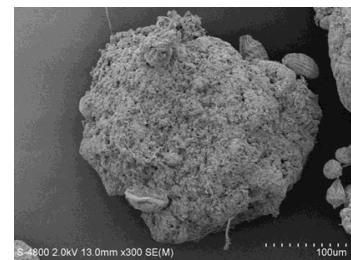

b. $5 \mathrm{mg} / \mathrm{L}$

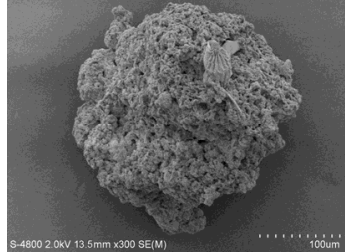

c. $10 \mathrm{mg} / \mathrm{L}$

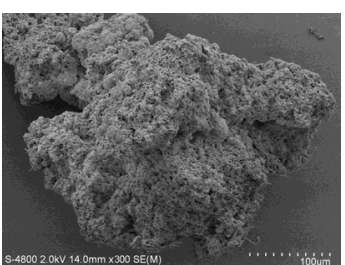

d. $20 \mathrm{mg} / \mathrm{L}$
Figure 3. High concentration $\mathrm{CuO}$ NPs impact on the 45th day AGS microstructure $\times 300($ SEM)

\subsection{EPS content under CuO NPs exposure}

The influence of different concentrations of $\mathrm{CuO}$ NPs on EPS content of DPR-AGS was shown in Figure 4. It can be seen that under the exposure to $5 \mathrm{mg} / \mathrm{L} \mathrm{CuO} \mathrm{NPs}$, the stability of DPR-AGS was less affected, and the production of proteins (PS) and polysaccharides (PN) is relatively stable. As can be seen from Table 1, PN/PS in EPS of granular sludge under the exposure to blank group and $5 \mathrm{mg} / \mathrm{L} \mathrm{CuO} \mathrm{NPs} \mathrm{basically} \mathrm{maintained} \mathrm{at} 1.21$ \pm 0.3 , indicating that granular sludge had certain resistance to low concentration $\mathrm{CuO}$ NPs. When the dosage of $\mathrm{CuO}$ NPs was increased to $10 \mathrm{mg} / \mathrm{L}$, the production of PS in granular sludge increased significantly, while PN/PS decreased. Under the condition of high PN/PS ratio, granular sludge has good relative hydrophobicity and stronger affinity between sludge. ${ }^{12}$ On the contrary, the smaller PN/PS value is, the worse for the stability of AGS. At the end of the stability study, PN/PS of $0,5,10$ and $20 \mathrm{mg} / \mathrm{L} \mathrm{CuO} \mathrm{NPs} \mathrm{were}$ $1.31,1.33,0.64$ and 0.52 respectively, and the stability of DPR-AGS was significantly decreased under the impact of high concentration $\mathrm{CuO}$ NPs.

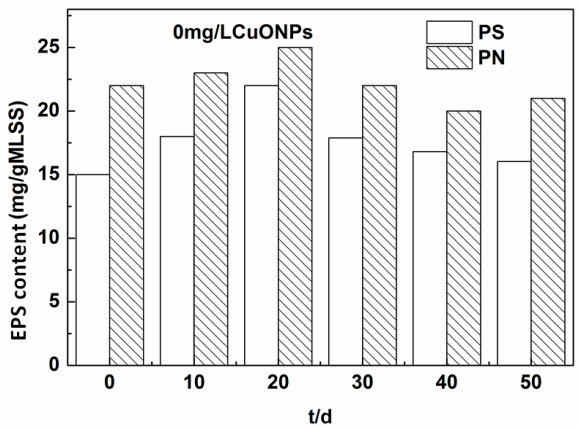

(a) $0 \mathrm{mg} / \mathrm{L} \mathrm{CuO} \mathrm{NPs}$

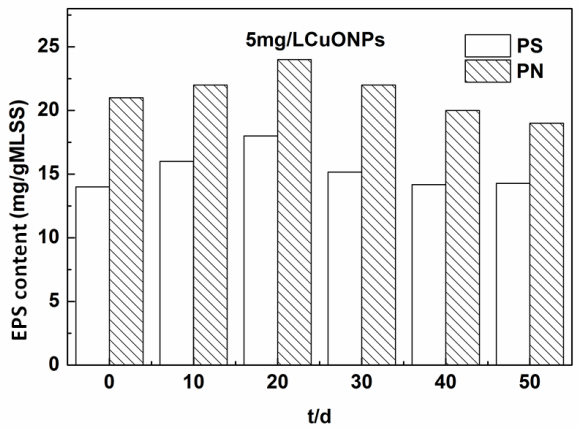

(b) $5 \mathrm{mg} / \mathrm{L} \mathrm{CuO} \mathrm{NPs}$ 


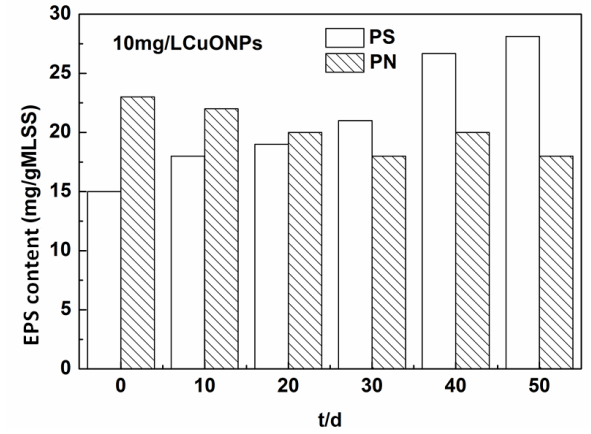

(c) $10 \mathrm{mg} / \mathrm{L} \mathrm{CuO} \mathrm{NPs}$

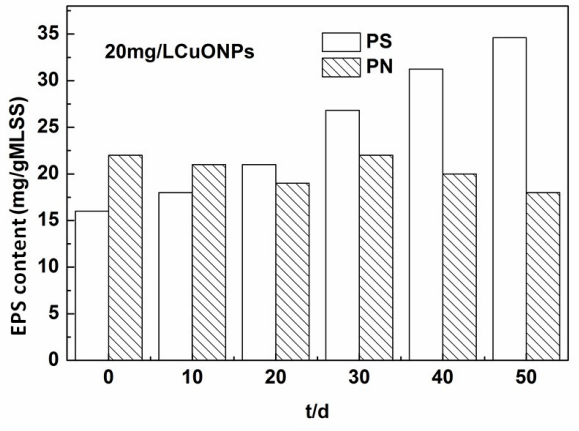

(d) $20 \mathrm{mg} / \mathrm{L} \mathrm{CuO} \mathrm{NPs}$

Figure 4. Effects of CuO NPs on EPS concents of AGS.

Table 1. The PS/PN ratio

\begin{tabular}{ccccc}
\hline \multirow{2}{*}{ Time $(\mathrm{d})$} & \multicolumn{5}{c}{ CuO NPs Concentrations (mg/L) } \\
\cline { 2 - 5 } & 0 & 5 & 10 & 20 \\
\hline 0 & 1.47 & 1.50 & 1.53 & 1.38 \\
10 & 1.28 & 1.38 & 1.22 & 1.17 \\
20 & 1.14 & 1.33 & 1.05 & 0.90 \\
30 & 1.23 & 1.45 & 0.86 & 0.82 \\
40 & 1.19 & 1.41 & 0.75 & 0.64 \\
50 & 1.31 & 1.33 & 0.64 & 0.52 \\
\hline
\end{tabular}

Table 2. Similarity-based OTUs and species diversity estimates for microbial communities in SBRs at different CuO NPs concentrations

\begin{tabular}{cccccccc}
\hline CuO NPs $(\mathrm{mg} / \mathrm{L})$ & Reads & OTUs $^{\mathrm{a}}$ & Coverage $^{\mathrm{b}}$ & Chao $^{\mathrm{c}}$ & Ace $^{\mathrm{c}}$ & Shannon $^{\mathrm{d}}$ & Simpson $^{\mathrm{d}}$ \\
\hline 0 & 39766 & 2318 & 0.95 & 195153.73 & 50494.36 & 4.15 & 0.08 \\
5 & 42083 & 2173 & 0.97 & 167887.18 & 46165.42 & 3.78 & 0.11 \\
10 & 36829 & 1887 & 0.97 & 142631.12 & 38357.17 & 3.15 & 0.14 \\
20 & 31271 & 1653 & 0.96 & 108652.51 & 30365.58 & 2.58 & 0.18
\end{tabular}

${ }^{a}$ OTUs: operational taxonomic units. ${ }^{\mathrm{b}}$ Coverage: estimates the possibility that the next read will belong to a specific OTU. ${ }^{c}$ Chao/Ace diversity estimator: total amount of OTUs estimated by infinite sampling. A higher number reflects more diversity. ${ }^{\mathrm{d}}$ Shannon/Simpson index: index to characterize species diversity.

\subsection{Microbial diversity of DPR-AGS}

High-throughput sequencing of the four sludge samples yielded a total of 15,621 effective sequences, and the effective sequences in the sludge samples with $0,5,10$ and $20 \mathrm{mg} / \mathrm{L} \mathrm{CuO} \mathrm{NPs} \mathrm{concentrations} \mathrm{were} \mathrm{39766,}$ 42083, 36829 and 31271. The microbial diversity index of DPR-AGS under the exposure to $\mathrm{CuO}$ NPs with different concentrations was shown in Table 2.

According to the diversity index Table 2, the OTU number of sludge samples with the $\mathrm{CuO}$ NPs concentration of $0,5,10$ and $20 \mathrm{mg} / \mathrm{L}$ was 2318,2173 , 1887 and 1653, respectively. With the increase of the $\mathrm{CuO}$ NPs concentration, the OTU number of sludge samples decreased. The variation trend of Ace and Chao index with the concentration of $\mathrm{CuO}$ NPs was the same with the change of OTU number. Compared with the blank group with the concentration of $\mathrm{CuO}$ NPs of 20 $\mathrm{mg} / \mathrm{L}$, the Ace and Chaol index of the blank group have decreased by $39 \%$ and $44 \%$, indicating that the abundance of bacteria in DPR-AGS decreases with the increase of the concentration of CuO NPs. Shannon and Simpson indices reflect the diversity of bacterial flora between different sludge samples. It can be seen that the Shannon index of the control group was the highest while the Simpson index was the lowest. As the concentration of $\mathrm{CuO}$ NPs increased, the Shannon index of the sludge samples decreased while the Simpson index increased, indicating that the addition of $\mathrm{CuO}$ NPs reduced the diversity of microbial flora of DPR-AGS. When the concentration of $\mathrm{CuO}$ NPs increased from 0 to $5 \mathrm{mg} / \mathrm{L}$ and from $10 \mathrm{mg} / \mathrm{L}$ to $20 \mathrm{mg} / \mathrm{L}$, the corresponding Shannon index decreased by $9 \%$ and $18 \%$, respectively. 
The high concentration of $\mathrm{CuO}$ NPs significantly reduced the microbial diversity of DPR-AGS.

The microbial population richness of DPR-AGS under the exposure to $\mathrm{CuO}$ NPs with different concentrations at the phylum level was shown in Figure 5. A total of 24 categories were detected in the 4 samples, and the ones with large abundance ratios mainly included Proteobacteria, Bacteroidetes, Planctomycetes, Verrucomicrobia, Candidate and Planctomycetes. Compared with microbial populations of AGS formed under $\mathrm{CuO}$ NPs stress, the major microbial populations of the two species had little difference in phylum level. As can be seen from Figure 5, the samples of DPR-AGS with different concentrations of $\mathrm{CuO}$ NPs were all the dominant strains of Proteobacteria. When the concentration of $\mathrm{CuO}$ NPs was $0,5,10$ and $20 \mathrm{mg} / \mathrm{L}$, the proportion of proteobacteria in the total sequence number in each sludge system was $72.62 \%, 68.91 \%, 63.73 \%$ and $54.54 \%$. Bacteroidetes was the second most bacteria in the system, from gate level species richness Bacteroidetes abundance with the rising of nanometer material additive concentration increased, $\mathrm{CuO}$ NPs pollutant concentration of $20 \mathrm{mg} / \mathrm{L}$ Bacteroidetes abundance rose by $13.68 \%$ in the blank group, explain Bacteroidetes of $\mathrm{CuO}$ NPs has good tolerance and adaptability. Planctomycetes is a common microorganism in sewage treatment system. As shown in Figure 5, when the concentration of $\mathrm{CuO}$ NPs increased, the abundance of Planctomycetes went through the process of increasing and then decreasing. When the concentration of $\mathrm{CuO}$ NPs was $10 \mathrm{mg} / \mathrm{L}$, the abundance of Planctomycetes decreased by $3.96 \%$. It indicated that $10 \mathrm{mg} / \mathrm{L} \mathrm{CuO} \mathrm{NPs} \mathrm{started} \mathrm{to} \mathrm{exert} \mathrm{significant} \mathrm{inhibition}$ on Planctomycetes microorganisms in the system. As the concentration of $\mathrm{CuO}$ NPs increased, microbes with poor adaptability to $\mathrm{CuO}$ NPs began to be gradually eliminated. As can be seen from the variation of microbial abundance with the concentration of $\mathrm{CuO}$ NPs, Bacteroidetes could better adapt to the impact of high concentration of $\mathrm{CuO}$ NPs than Planctomycetes.

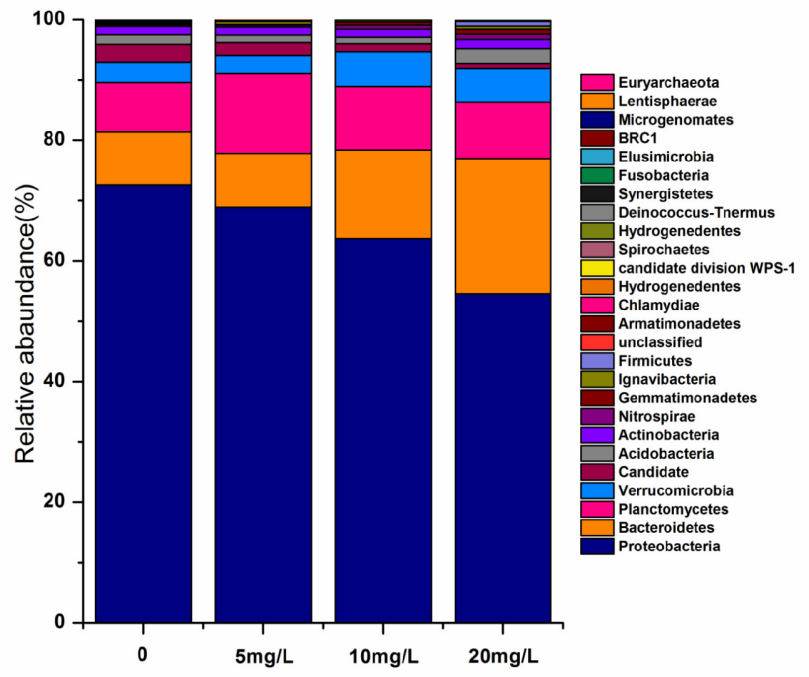

Figure 5. Relative distribution of bacterial genus for the four AGS samples at the end of the exposure.

\section{Conclusion}

(1) Under the exposure to 0, 5, 10 and $20 \mathrm{mg} / \mathrm{L} \mathrm{CuO} \mathrm{NPs,}$ the removal rate of COD in each reactor remained at 95.2 $\pm 0.8 \%$, and the effect of DPR-AGS with different concentrations of $\mathrm{CuO}$ NPs on COD removal effect was small. At the end of the experiment, the effluent concentration of $\mathrm{TN}$ in the reactor under the exposure to high concentration $\mathrm{CuO}$ NPs increased, and the high concentration of $\mathrm{CuO}$ NPs reduced the removal effect of DPR-AGS on TN. After the operation of each reactor for $15 \mathrm{~d}$, the TP concentration in the effluent was basically maintained at $1 \pm 0.5 \mathrm{mg} / \mathrm{L}$. Thus, the DPR-AGS had certain resistance to the short time impact of $\mathrm{CuO}$ NPs. At the end of the impact test, the TP removal efficiency of the reactors with the concentration of $10 \mathrm{mg} / \mathrm{L}$ and $20 \mathrm{mg} / \mathrm{L}$ of $\mathrm{CuO}$ NPs decreased to $55.83 \%$ and $43.72 \%$, and the phosphorus removal capacity of AGS under the exposure to high concentration $\mathrm{CuO}$ NPs decreased at the later stage of the impact test.

(2) The increase of PN/PS ratio can improve the relative hydrophobicity of granular sludge and enhance the affinity between sludge. The smaller the PN/PS ratio is, the worse it is for the stability of AGS. At the end of the stability study, PN/PS of $0,5,10$ and $20 \mathrm{mg} / \mathrm{L} \mathrm{CuO}$ NPs were $1.31,1.33,0.64$ and 0.52 respectively. The stability of DPR-AGS was significantly decreased under the impact of high concentration $\mathrm{CuO}$ NPs.

(3) When the concentration of $\mathrm{CuO}$ NPs increased from 0 to $5 \mathrm{mg} / \mathrm{L}$ and from $10 \mathrm{mg} / \mathrm{L}$ to $20 \mathrm{mg} / \mathrm{L}$, respectively, the corresponding Shannon index decreased by $9 \%$ and $18 \%$. High concentration of $\mathrm{CuO}$ NPs significantly reduced the microbial diversity of DPR-AGS. As can be seen from the variation of microbial abundance with the concentration of $\mathrm{CuO}$ NPs, Bacteroidetes is more adapted to the impact of high concentration of $\mathrm{CuO}$ NPs than Planctomycetes.

\section{References}

1. M. Heinlaan, A. Ivask, L. Blinova, H. Dubourguier, A. Kahru. Toxicity of nanosized and bulk $\mathrm{ZnO}, \mathrm{CuO}$ and $\mathrm{TiO}_{2}$ to bacteria Vibrio fischeri and crustaceans Daphnia magna and Thamnocephalus platyurus. Chemosphere 2008, 71, 1308-1316.

2. N. Adam, A. Vakurov, D. Knapen, R. Blust. The chronic toxicity of $\mathrm{CuO}$ nanoparticles and copper salt to Daphnia magna. J. Hazard. Mater. 2015, 283, 416-422.

3. M. Mortimer, K. Kasemets, A. Kahru. Toxicity of ZnO and $\mathrm{CuO}$ nanoparticles to ciliated protozoa Tetrahymena thermophilia. Toxicology. 2010, 269, 182-189.

4. R. Ganesh, J. Smeraldi, T. Hosseini, L. Khatib, B. H. Olson, D. Rosso. Evaluation of Nanocopper Removal and Toxicity in Municipal Wastewaters. Environ. Sci. Technol. 2010, 44, 7808-7813.

5. S. Wagner,A. Gondikas, E. Neubauer, T. Hofmann,F. von der Kammer. Spot the difference: engineered and natural nanoparticles in the environment-release, 
behavior, and fate. Angew Chem Int Ed Engl. 2014, 53, 12398-12419.

6. F. Tou, Y. Yang, J. Feng, Z. Niu, H. Pan, Y. Qin, X. Guo, X.Z. Meng, M. Liu, M.F. Hochella. Environmental Risk Implications of Metals in Sludges from Waste Water Treatment Plants: The Discovery of Vast Stores of Metal-containing Nanoparticles. Environmental Science \& Technology. 2017, 51, 4831-4840.

7. O. Bondarenko, K. Juganson, A. Ivask, K. Kasemets, M. Mortimer, A. Kahru. Toxicity of $\mathrm{Ag}, \mathrm{CuO}$ and $\mathrm{ZnO}$ nanoparticles to selected environmentally relevant test organisms and mammalian cells in vitro: a critical review. Arch. Toxicity. 2013, 87, 1181-1200.

8. P. Mwaange, E.R. Carraway, P. van den Hurk. The induction of biochmeical changes in Daphnia magna by $\mathrm{CuO}$ and $\mathrm{ZnO}$ nanoparticles. Aquat. Toxicol. 2014, 150, 201-209.

9. D. Wei, M. Li, X. Wang, et al. Extracellular polymeric substances for $\mathrm{Zn}$ (II) binding during its sorption process onto aerobic granular sludge. J. Journal of Hazardous Materials. 2016, 301, 407-415.

10. X. Y. Zheng, X. N. Wang, X. Huang, et al. Effects of $\mathrm{Cu}^{2+}$ on morphological structure, functional groups, and elemental composition of aerobic granular sludge. J. Environmental Technology. 2013, 34(2), 219-224.

11. A. A. Keller, S. McFerran, A. Lazareva, S. Suh. Global life cycle releases of engineered nanomaterials. J. Nanopart. Res. 2013, 15, 15.

12. A. Bradford, R. D. Handy, J. W. Readman, A. Atfield, M. Muhling. Impact of silver nanoparticles contamination on the genetic diversity of natural bacterial assemblages in estuarine sediments. Environ. Sci. Technol. 2009, 43, 4530-4536. 